\title{
POEMS
}

\section{DESERT RATS}

An hour to spare this pen and me A word I'll pen whilst thoughts are free To write, and pay those "Rats" their due As we know them, me and you.

Hard and lean, covered in sand Fast and sure. Gad! what a band, That dirty but efficient lot

And "Desert Rats" that name they've got.

I met a Cockney who says he's a "wiv" That bloomin Seventh Armoured Div Their prestige coudn't change somehow With nearly all new faces now.

With modest air, they mention places Where Rommel saw their dirty faces Unshaved and scruffy, eyes red rimmed They don't use language finely trimmed.

And when the dust blows like a cloud I'm sure its nectar to that crowd

Fast and true on the "blue"

Fords and Chevis gliding through.

When these days are o'er and done Like a dust storm's death in the setting sun And desert nights are quiet and cold The Deeds they've done will still be told.

In whistling sand, or Barcia's gate Tobruk, Mechili its their Fate Their ghosts will haunt each battle ground On which the "Desert Rats" were found.

*Author unknown. 